\title{
PROSPECTIVE MADM AND SENSITIVITY ANALYSIS OF THE EXPERTS BASED ON CAUSAL LAYERED ANALYSIS (CLA)
}

\section{Sarfaraz Hashemkhani Zolfani', Morteza Yazdani², Edmundas Kazimieras Zavadskas ${ }^{3}$, Hamidreza Hasheminasab ${ }^{4}$}

\footnotetext{
1 Catholic University of the North, School of Engineering, Chile, ORCID: 0000-0002-2602-3986, sa.hashemkhani@gmail.com;

2 Universidad Loyola Andalucía, Department of Management, Spain, ORCID: 0000-0001-5526-8950, morteza_yazdani21@yahoo.com;

3 Vilnius Gediminas Technical University, Institute of Sustainable Construction, Lithuania, ORCID: 0000-0002-3201949X, edmundas.zavadskas@vgtu.lt;

4 University of Tehran, School of Civil Engineering, College of Engineering, Iran, Hasheminasab@ut.ac.ir.
}

\begin{abstract}
Multiple Attribute Decision Making (MADM)" is an expert based field which is working based on real data and experts' opinions. So many studies have been doing based on MADM methods which they usually use qualitative data based on experts' ideas. Decisions based on the experts' opinion shall be carefully designed to cope the real problems uncertainty. This uncertainty will be even more intricate if combining the problem with the ambiguity of the future study. Prospective MADM is a future based type of MADM field which is concentrating on decision making and policy making about the future. Prospective MADM (PMADM) can have both explorative and descriptive paradigms in the studies but it will more useful to be applied for strategic planning. In this regard, experts' role would be even more challenging because one/some possible future/ futures will be partially designed based on their opinions. Future and prediction always complicates the decision environment, especially methodologies founded on experts' judgement. Considering experts' preferences, attitude, and background, they may be a major source of inaccurate results. Causal Layered Analysis (CLA) is well-known "Futures Studies" method which is qualitative and usually is supporting other methods such as "Backcasting" and "Scenario Planning". CLA has a deep point of view to the subjects to support a future with all those changes which are necessary for the main goal/goals. In this study, this idea will be proposed that CLA can be added to PMADM outline to decrease the risk of unsuitable decisions for the future and for this aim a case study about energy and $\mathrm{CO}_{2}$ consumption in policy making level proposed and a hybrid MADM method based on BWM-CoCoSo applied in the PMADM outline for the procedure.
\end{abstract}

Keywords: Prospective Multiple Attribute Decision Making (PMADM), sensitivity analysis, experts, Causal Layered Analysis (CLA), Best Worst Method (BWM), COmbined COmpromise SOlution (CoCoSo).

JEL Classification: Q48, Q56, C91.

APA Style Citation: Hashemkhani Zolfani, S., Yazdani, M., Zavadskas, E. K., \& Hasheminasab, H. (2020). Prospective MADM and Sensitivity Analysis of the Experts Based on Causal Layered Analysis (CLA). E\&M Economics and Management, 23(3), 208-223. https://doi.org/10.15240/ tul/001/2020-3-013

\section{Problem Definition}

Multiple Attribute Decision Making (MADM) methods have been working by real data and qualitative analysis of experts' ideas. It is really difficult and complicated to find more related experts to a topic which is solving but still there is a bigger challenge which is experts' backgrounds. In so many cases there are so 
many experienced experts but their attitudes are very dissimilar and diverse. It can be said that none of their ideas are incorrect but do they have a well-defined perspective to the main subject? Maybe based on so many limitations there is not enough chance to check their consistency rate about an issue but it is possible to make a higher consistency based on a pre-plan. Mostly, only investigators have enough knowledge about a new research because they are defining and illustrating it in different dimensions of the topic. Usually, for solving multi-attribute problems, investigators do not explain and express their exact ideas to the experts because of so many challenges and limitations such as time and other topics. Causal Layered Analysis (CLA) is a really helpful approach and method in defining a topic in depth. CLA is a method of Futures Studies field which is really useful in decision making, policy making and generally long-term planning. As everyone knows, our decisions today are making for the future whether shortterm, medium-term or long-term.

Based on a well-prepared CLA outlook which shows a depth in its four levels, there is an opportunity to express exact point of view about the study to the experts from investigators side. The investigators can also examine the general paradigm of the researchers based on CLA analysis. This is really vital to have some experts who are really connected to the main idea, methodology and paradigm of the study. This is an advantage which CLA can guarantee it for the mentioned aim. This study is trying to show how much selecting experts is an important step which should be considered more in the MADM studies to increase the quality and output of a MADM challenge. Prospective MADM as a new approach has been developing lately. The classic outline of MADM is expanding based on PMADM approach and some new items have been adding to the old structure. One of another point which is really critical for the new approach is who are creating a future which has a core paradigm inside. So, CLA in general can be suitable for classic MADM but it has bigger influences and impacts on outputs of PMADM approach because PMADM proposed to solve bigger and more long-term challenges and problems. In this study, the process of experts' selection in PMADM outline will be discussed. To support this idea, Casual Layered Analysis (CLA) is applied to illustrate a deep perspective in this procedure. This idea will be discussed with a real case study and based on a new hybrid MADM method, BWMCoCoSo, will be analyzed.

\section{Literature Review on Sensitivity Analysis and MADM Studies}

All studies related to the sensitivity about MADM field can be categorized in two main categories.

First category: Those studies which are working on presenting a new way to add a sensitivity analysis to a common MADM method. Mostly, those studies proposed when researchers were using more than a method for solving the problems. It can be said that the main idea is to check robustness rate of results.

Triantaphyllou and Sanchez (1997) presented a sensitivity analysis for some deterministic methods such as: Weighted Sum Model (WSM), Weighted Product Model (WPM) and Analytic Hierarchy Process (AHP). Zavadskas et al. (2007) presented a new sensitivity analysis on SAW method but the idea was to check the role of criteria and normalization methods especially Linear Normalization. Toloie Eshlaghy et al. (2009) proposed a sensitivity analysis on criteria values in decision making matrix of SAW method based on calculations about deviation. Yazdani et al. (2016) applied different type of normalizations for the sensitivity analysis. MOORA and WASPAS were in the core of this research and their results with different normalization ways have compared. Pamučar et al. (2017) presented a new model for consistency evaluation of MADM methods for selecting an optimum option as an alternative. The model examined on some common MADM methods alike TOPSIS, COPRAS, VIKOR and ELECTRE. Mukhametzyanov and Pamučar (2018) proposed a new sensitivity model for MADM methods. The study developed based on the idea of working on top three alternatives based on final ranking and especially those cases which top three alternatives are not so much different. The model examined on several common MADM methods such as SAW, MOORA, VIKOR, COPRAS, CODAS, MABAC, PROMETHEE-I, II, and ORESTE-II.

Second category: Those studies which are concentrating on sensitivity analysis inside the original methods. It means some methods have been presented with the kind of sensitivity analysis which is mostly inconsistency rate. 
It can be said that all methods such as Analytic Hierarchy Process (AHP) (Saaty, 1980), Analytic Network Process (ANP) (Saaty, 1996; 1999), Factor Relationship (FARE) (Ginevicius, 2011), Best Worst Method (BWM) (Rezaei, 2015) and Full Consistency Method (FOCUM) (Pamučar et al., 2018) which are working based on pairwise comparisons are working based on consideration of inconsistency rate of experts' ideas and main goal in mentioned method was decreasing inconsistency of ideas in practice. Hashemkhani Zolfani et al. (2018a) also presented a new extended version of SWARA method and this sensitivity analysis applied on experts' ideas to examine the results.

\section{Methodology}

In this part three sections will be presented as follow: 1. "Causal Layered Analysis (CLA)", 2. "Why CLA?", and 3. "Prospective MADM".

\subsection{Causal Layered Analysis (CLA)}

Firstly, CLA was introduced as one of Futures Studies method around two decades ago with this goal to create transformative spaces for making future alternatives instead of predicting the futures (Inayatullah, 1998). CLA is kind of communicative method that applies storytelling and narrative to consider and build all possible and probable futures (Heinonen et al., 2017). This method established and influenced by post-structural theory which illustrates and explores these causal layers in four levels and separate-deep layers (Milojević, 2015). These four levels are illustrated in Fig. 1.
1. "Litany" refers to those topics which usually consider as those "facts" that hardly ever proved, confirmed or asked. 2. "Social causes" focuses on system's paradigm and perspective on different topics such as political and cultural attributes, social issues, economic and eventually clarify behavioral rules back behind of the litany level. 3. "Discourse" illustrates important impressions that are historical, social and has great multi-dimensional impact on common logic, sense, values, worldviews and paradigms. 4. "Metaphors and Myths" which demonstrates storylines and wrong information and data which usually people and societies are justifying themselves (Milojević \& Inayatullah, 2015).

\subsection{Why CLA?}

CLA is recognized by its criticizing paradigm as a futures research method which is working based on an understandable point of view about futures changes. This method is applying based on a core assumption about framing a challenge or a problem and considering its impact about how the probable changes will be followed (Ramos, 2003). CLA highlights the status of understanding the reality based on different layers of seeing and knowing things (KetonenOksi, 2018). CLA has this potential to integrate other tools and methods and at the same time it is flexible to be integrated with other methods such as Scenario Planning and Backcasting. CLA is really helpful to be applied in emerging issues to present a better point of view about different topics (Ketonen-Oksi, 2018).

\section{Fig. 1: CLA's levels}

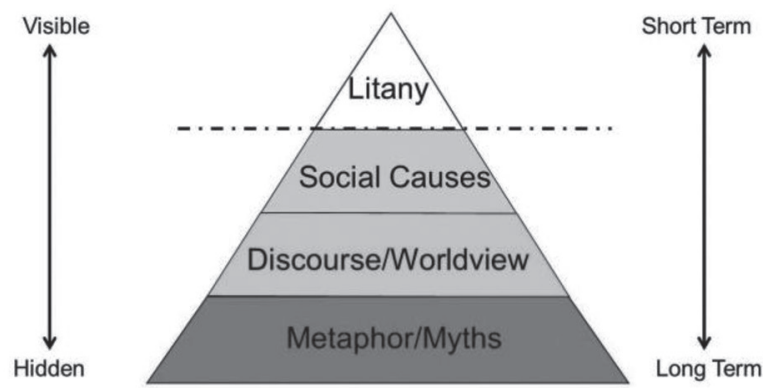


CLA has not applied with MADM methods since now and the application of that in the main procedure of solving a MADM problem will be unique and useful. According to the related literature of MADM methods, there is not a special trend related to the experts selecting process. Although solving a MADM problem based on different mathematical perspectives is important, selecting the experts seem more critical in reality. Those qualitative numbers which experts can select can even change the destiny of a nation. CLA is able to prove that a study is using an appropriate group of experts which they are able to see a problem from the eye of researchers related to the main set of goals.

\subsection{Prospective MADM}

During last decade, time importance and considering the future became a major topic in the field of Multiple Attribute Decision Making (MADM) and they also contained some new approaches such as Dynamic MADM and MADM based on Scenarios (Trutnevyte et al., 2012; Arms et al., 2012; Zhang, 2012; Durbach \& Stewart, 2012; Hashemkhani Zolfani et al., 2013; Wang et al., 2014; Tadić et al., 2014;
Gonzalez-Prida et al., 2014; Ondrus et al., 2015; Jassbi et al., 2014; Hashemkhani Zolfani et al., 2016a; Siddiqi et al., 2016).

Prospective MADM is a new approach for decision making about future-related or future-based problems which they need to be solved in the multi-attribute framework (Hashemkhani Zolfani et al., 2016b). There was a need for consideration future orientations in the common decision making structure and especially in MADM methods and framework. Therefore, PMADM it can be seen as a new approach which can cover all future-based and multi-attribute problems because is working as a platform which is not limited to a special space (Hashemkhani Zolfani et al., 2016c).

PMADM presented in a multi-disciplinary research area which it meets Multiple Criteria Decision Making (MCDM) and its bigger picture which is Operations Research (OR) and Futures Studies, Foresight and its smaller picture Strategic Management. As it mentioned above, PMADM is a platform which has a new approach and it has a great potential to be considered an inter-disciplinary research field in the future (Hashemkhani Zolfani, 2018b).

\section{Tab. 1: PMADM model based on future limitations}

\begin{tabular}{|c|c|c|c|c|c|c|}
\hline \multirow{2}{*}{\multicolumn{7}{|c|}{ Weights }} \\
\hline & & & & & & \\
\hline \multirow[t]{2}{*}{$\begin{array}{l}\text { Limiters (L)/ } \\
\text { Boosters (B) }\end{array}$} & & $L_{1-1} \ldots L_{1-n}$ & & $L_{n+1-1} \ldots L_{n+1-n}$ & & $L_{n-1} \ldots L_{n-n}$ \\
\hline & $\begin{array}{l}\text { Based } \\
\text { on } C_{1}\end{array}$ & Average & $\begin{array}{l}\text { Based } \\
\text { on } C_{n+1}\end{array}$ & Average & $\begin{array}{l}\text { Based } \\
\text { on } C_{n}\end{array}$ & Average \\
\hline \multicolumn{7}{|l|}{$\overline{A_{1} \text { without } L}$} \\
\hline \multicolumn{7}{|l|}{$A_{1}$ based on $L_{1-1}$} \\
\hline \multicolumn{7}{|l|}{$\mathrm{A}_{1}$ based on $\ldots$} \\
\hline \multicolumn{7}{|l|}{$A_{1}$ based on $L_{1-n}$} \\
\hline \multicolumn{7}{|l|}{$A_{n+1}$ without $L$} \\
\hline \multicolumn{7}{|l|}{$A_{n+1}$ based on $L_{n+1-1}$} \\
\hline \multicolumn{7}{|l|}{$A_{n+1}$ based on $\ldots$} \\
\hline \multicolumn{7}{|l|}{$A_{n+1}$ based on $L_{n+1-n}$} \\
\hline \multicolumn{7}{|l|}{$A_{n}$ without $L$} \\
\hline \multicolumn{7}{|l|}{$A_{n}$ based on $L_{n-1}$} \\
\hline \multicolumn{7}{|l|}{$A_{n}$ based on ... } \\
\hline$A_{n}$ based on $L_{n-n}$ & & & & & & \\
\hline
\end{tabular}


The all new contributions of PMADM based on new items based on classic form of MADM are presented below:

1. Limiters/Boosters: Hashemkhani Zolfani et al. (2016b) presented the first new item in PMADM framework which can be called Limiters/Boosters. Limiters/Boosters can have the role of pay-offs of future scenarios for the evaluating alternatives in their positions. It can be illustrated where they are locating in the structure of a classic MADM framework as an example in the Tab. 1.

Tab. 1 is designed for the Limiters. Boosters can be put the same in the table. Pay attention that Limiters and Boosters can both apply at the same time in the process of decision making for decision making about the future because it can be happened in reality. Future probability also can be added to the process and all it can be measured as an introduction to the PMADM. Other items can be attached and added to the classic structure of PMADM to have a better outcome in evaluating criteria, relative weights and other probable calculations of the MADM framework.

2. Multi-aspect Criterion: is a new item in classic structure of MADM in PMADM area. It contains two main shapes of: "Hybrid criteria as a new criterion" and "a lately defined concept for the other criteria as a criterion". The importance of time will be showed with this new item to control the definitions during the years. In future definitions and criteria can be mixed or developed in different aspects and approaches. It is really important to have an explicit definition about a certain time in the future while the decision making process is happening (Hashemkhani Zolfani et al., 2018b).

3. Supportive-backup criteria: is another additive item to PMADM outline. While different future scenarios are considering, this new item can be really useful. It shapes all future decision making matrix in a one matrix and decision makers can shape to whatever they want and make their decision better and more effective (Hashemkhani Zolfani \& Masaeli, 2019). An example is shown is Tab. 2.

\section{Possible Structures}

Generally, MADM is really dependent to the expert's ideas and do many sensitivity analysis have been doing to check if the final answer based on experts' opinions is reliable or is not possible to be counted as a consistent result. The process of selecting the experts is a really challenging procedure and usually it works in two main categories. In solving a problem usually knowledge of different fields will be needed. Therefore, the general concept and paradigm behind of each field would be really critical and vital for the investigators. Another key point is the expert, itself. When someone is selected, it does not mean necessarily he/she is coming from the paradigm which investigators are looking at it. Finally, these two main categories can be divided in two main sections as:

\section{A position as chair of a field}

This section will be discussed based on some simple examples.

\section{Tab. 2: Position of "Supportive-backup" criteria}

\begin{tabular}{l|l|l|l|l}
\multirow{4}{*}{$\begin{array}{c}\text { Supportive-backup } \\
\text { criteria }\end{array}$} & $\mathbf{C}_{1}$ & $\mathrm{C}_{2}$ & $\mathrm{C}_{\mathrm{n}-1}$ & $\mathrm{C}_{\mathrm{n}}$ \\
\cline { 2 - 5 } & $\mathrm{C}_{\mathrm{s} 1-1}$ & $\mathrm{C}_{2^{*} \mathrm{~s} 1}$ & $\mathrm{C}_{\mathrm{s} 1-\mathrm{n}-1 \mathrm{~s} \mathrm{~s} 1}$ & $\ldots$ \\
\cline { 2 - 5 } & $\mathrm{C}_{\mathrm{s} 2-1}$ & $\mathrm{C}_{\mathrm{s} 1-2}$ & $\mathrm{C}_{\mathrm{n}-1^{*} \mathrm{~s} 2}$ & $\ldots$ \\
\cline { 2 - 5 } & $\mathrm{C}_{\mathrm{u} 1-1}$ & $\ldots$ & $\ldots$ & $\ldots$ \\
\hline $\mathrm{A}_{1}$ & $\ldots$ & $\ldots$ & $\ldots$ & $\ldots$ \\
\hline Reserved $\mathrm{A}_{1}$ & $\ldots$ & $\ldots$ & $\ldots$ & $\ldots$ \\
\hline Reserved $\mathrm{A}_{1}$ & $\ldots$ & $\ldots$ & $\ldots$ & $\ldots$ \\
\hline Reserved $\mathrm{A}_{1}$ & $\ldots$ & $\ldots$ & $\ldots$ & $\ldots$ \\
\hline$\ldots$ & $\ldots$ & $\ldots$ & $\ldots$ & $\ldots$ \\
\hline$\ldots$ & $\ldots$ & $\ldots$ & $\ldots$ & $\ldots$ \\
\hline $\mathrm{A}_{\mathrm{n}}$ & $\ldots$ & $\ldots$ & $\ldots$ & $\ldots$ \\
\hline
\end{tabular}


First example: Future sustainability: Consider an expert from Economic field who believes on short-term profits as it can be seen as a general policy of some countries as different strategies. In this case, investigators are inviting a person who should lead a research on sustainability path with his/her qualitative numbers in MADM field. Consider all topics about the future need a long-term point of view and will not be achievable with whom they do not believe in that.

Second example: Education and future generations: A comparison between education system of some countries show that probably related politicians have a bios on their systems. Considering Japan, Finland, the USA or Chile shows a huge different in the systems and designing new policies should be really independent from what countries are applying as their policies. Is not possible to invite from a person who does not believe in a different future which that study can guaranty a better life for the society.

Third example: Structure of policy making: Experts like normal people can have their ideology or paradigm about everything. Now, consider political parties, ideological governments and groups and people who believe or not believe in the common political structures. All related topics to the goal of studies which investigators are following have interconnected to so many aspects and dimensions. This issue that investigators should know more about experts' background is a real challenge for the decision making processes especially topics related to the futures.

2. General characteristics of the expert

Some experts necessarily are not coming from obvious backgrounds. In so many cases experts do not have enough information and knowledge about what investigators are going to do because most the time researchers are working on new topics which can be not so common but what is necessary is different knowledge from different research fields and areas. CLA can be useful in these two categories. It can be seen what experts are thinking about a study when their general point of view and paradigm will be examinable. CLA gets this chance to the researchers to find the most suitable experts to their studies. Another point can be noticed that, in so many cases researchers need different point of view. In this case and by CLA researchers can be sure about what they need about different point of views. It means if you there is a need for different ideas about something it can be definitely findable.

\section{CLA in Practice}

The idea is to evaluate experts in four levels of CLA but the first and second level can be what we can define and get easily from the ideas, easily. It feels Worldview level and myth and metaphor levels need more attention. For this mean, a case as an example will be considered. Baradaran Ghahfarokhi et al., (2018) applied CLA method for planning the future of the University of Tehran. Is this study, common levels have analyzed (How is it now?) and defined another four levels (what should be?). It shows that moving to a future it needs changes in different levels and shifting in paradigms mostly are needed. In this section some of the most important points as sample will be evaluated:

- In systematic causes, multi-source of financing and internationalization were mentioned.

This is a part of the plan which researchers reached to that so all decisions should be lead to this goal of the second level.

What if an expert did not believe in free international relationships? What if an expert still believes in governmental financial supports?

- In worldview level, it mentioned if you as a university are not going to invest on new technologies, you will be left behind.

But what if political or ideological ideas come inside? Iran had a not suitable experience in producing airplanes. What will happen if the expert has preferences on special field? Any conflict of interest would be really dangerous for the future planning.

- In metaphor level: it stated that science and money together should be the goal and not only science for science for science only for money.

But most of people are thinking like that but in reality so many of them cannot think like that. This idiom which says that science is better than money is still common in the society. Meanwhile, because of bad financial situation some people are thinking completely different and they gave up. They prefer to follow the money way so they do not believe in science anymore. So, it is really challenging to find those experts who have a really clear background and probably they should be those specialists in their fields who could earn a considerable amount of money. 
As it mentioned about outputs of what the University of Tehran should be changed for a brighter future, it can be said that in solving current problems of the university experts can have a great role. In this section some points will be discussed.

- Political issues are really related to the managing system of the university. So, researchers should be sure about experts' perspectives. Those experts who are thinking politically cannot be good options.

- For example in the mentioned study of Baradaran Ghahfarokhi et al. (2018), former ministers of science, research and technology were invited. The experiences would be really helpful but some positions had enough time to make some changes therefore, it seems better to invite more entrepreneurs and those who had some visits from the best universities of the world because future needs experience about what is going to happen and not only what is happened.

- Teamwork culture; experts should have good taste of doing teamwork. The process should be always with some feedbacks from researchers and other experts. This loop can guarantee a better decision and output about the future.

- Cultural habits and procedures; when there is a need for a radical change but some people which are experts for the researchers are deeply believed in some habits, procedures and routines.

- Knowledge about the future; The expert who is deciding about the future should know about what is happening in the world, all new trends, all new driving forces, newest strategies of universities, related multi-disciplinary fields, new international foresight programs, new international regulations, latest related publications and future of education in general.

\section{Possible Evaluation Ways}

There are so many ways for this evaluation about experts' paradigms and perspectives. Common ways of gathering data in qualitative studies would be helpful. The most important ones can be as follow:

- Background evaluation: Political background, past experiences, publications and all other documents and information which illustrate expert's point of view.
- Questionnaire: Based on questionnaires which main authors can prepare they can check experts' ideas about the topic. It can be useful for both sides because experts can understand the main idea and paradigm of the study really better.

- Interview: With an interview researchers can explain their goals and perspectives to the experts and at the same time can examine the experts' opinions according to the objectives. The key point is to have the same goals and in way of reaching to the goals they can be completely free to present different attitudes.

- Conference meetings: In a conference meeting investigators can present the main aim of the study and based on a dialogue among experts, researchers can select the most related experts among them for the study. It should not be a designed conference meeting from researchers' side and it can be a panel from other conference meetings or it can be a not organized meeting and can be done in random inside other related international or national conferences.

- A mix method: A mix of mentioned ways above researchers can analyze the experts in the more deeply way.

Experts have a really key role in solving MADM problems specially those which are completely to the long-term decisions. PMADM needs to be more robust in comparison to the classic MADM form of solving the problems. The role of experts can build and change the future for all so a new point of view, in this regard, will be inevitable.

\section{Case Study}

In this section, a case from energy sector has been selected. Energy is a critical issue in Iran which has huge gas and oil natural resources. Iran is one of the biggest $\mathrm{CO}_{2}$ producers in all around the world because of the heavy industries which it has. Based on Paris agreement's agenda Iran has to decrease four percent of producing $\mathrm{CO}_{2}$ until the end of 2020 and eight more percent till the end of 2030. Nowadays, Iran has so many polluted cities especially in winter periods. So, Iran like so many other countries has to do a strategic planning for the better air quality in the future. In this study, authors did not go deep inside the topic but some suggestions presented to some 
selected experts of energy which had some practical experiences and positions in related governmental organizations. On the other hand, some international experts were also selected to make a suitable combination.

In total, 20 experts have been invited which half of them were inside the country and the others were from outside the country. Among the experts, five experts were Iranians from outside the country and five were from other countries. To be clearer, authors did some interviews with them with an indirect way of asking about their ideas about the future of energy in Iran. The idea was to measure the main paradigm and background of them. To measure them better, authors tried to check what they think about the society, history of the country, international paradigm, general information about the country, general information about future of the energy and all other related topics which the experts would like to talk about that. So, it was not an open ended type of interview with them. Meanwhile, some main and key factors were defined by authors. Some factors such as: Believe in an international role of the country $\left(C_{1}\right)$, clean air as the human right $\left(C_{2}\right)$, moving to renewable energies in Iran $\left(C_{3}\right)$, investing more in renewable energies and all other new energies in the future $\left(C_{4}\right)$, moving to the more private economy in Iran $\left(C_{5}\right)$, decreasing dependency of economy to the oil $\left(\mathrm{C}_{6}\right)$, benchmarking from other successful economies like Norway $\left(\mathrm{C}_{7}\right)$, political trend of thinking (to be independent as much as possible) $\left(\mathrm{C}_{8}\right)$ and the paradigm to the Iranian exceptional national identity in the future $\left(\mathrm{C}_{9}\right)$.

\subsection{Best Worst Method (BWM)}

Rezaei (2015) configured a novel and applied decision analysis tool called BWM based on a linear programing perspective. BWM received considerable attentions in various fields (van de Kaa et al., 2017; Chitsaz \& Azarnivand, 2017). This method conveys the decision-making problem in order to find the weight and rank of decision criteria. The idea behind the BWM runs an operable model in complex decision environments (Rezaei et al., 2016). Wide range of applications employed BWM in different decision environments (Rezaei et al., 2015; Ahmadi et al., 2017; Gupta, 2018). To look for the impotence weights of decision criteria using BWM, the steps below must be followed:

Step 1 - Determining set of decision criteria: $\left\{c_{1}, c_{2}, \ldots, c_{\mathrm{n}}\right\}$;
Step 2 - Choosing the best and the worst criteria by decision maker (DM). The best criterion represents the most desirable or the most significant one while the worst criterion is the least important one among others;

Step 3 - Conducting the pairwise comparisons between the best criterion and the other criteria by DM. In this step, the goal is to identify the preference of the most important criterion to the other criteria. DM uses a scale from 1 to 9 (1: equally important, and 9: extremely more important). The comparison outcome is described as Best-to other vector: $A_{B}=\left(a_{B 1}, a_{B 2}, \ldots, a_{B n}\right)$, where $a_{B j}$ represents the preference of the best criterion $B$ over the criterion $j$ and $a_{B B}=1$;

Step 4 - The DM conducts pairwise comparison between the other criteria and the worst criterion. Same as last step, the comparison results are expressed by Other-toworst vector: $A_{W}=\left(a_{1 W}, a_{2 W}, \ldots, a_{n B}\right)^{T}$, where $a_{j W}$ represents the preference of the best criterion $j$ over the criterion $W$ and $a_{w W}=1$;

Step 5 - Calculating the optimal weights: $\left(W_{1}^{*}, W_{2}^{*}, \ldots, W_{n}^{*}\right)$. For each pair of $\frac{W_{B}}{W_{j}}$ and $\frac{W_{j}}{W_{W}}$, the optimal weight should meet the requirement that $\frac{W_{B}}{W_{j}}=a_{B j}$ and $\frac{W_{j}}{W_{W}}=a_{j W}$. To satisfy the conditions, the maximum absolute differences $\left|\frac{W_{B}}{W_{j}}-a_{B j}\right|$ and $\left|\frac{W_{j}}{W_{W}}-a_{j W}\right|$ for all $j$ is minimized. Also, taking into consideration the non-negativity characteristic and sum condition of the weights, the following problem can be formulated:

$$
\operatorname{Min} \max _{j}\left\{\left|\frac{W_{B}}{W_{j}}-a_{B j}\right|,\left|\frac{W_{j}}{W_{W}}-a_{j W}\right|\right.
$$

s.t:

$\sum_{j} W_{j}=1, W_{j} \geq 0$ for all $j$

If we transform the above model, we have the second equation:

$$
\begin{array}{cl}
\text { s.t: } & \min \xi \\
& \left|\frac{W_{B}}{W_{j}}-a_{B j}\right| \leq \xi, \quad \text { for all } j \\
& \left|\frac{W_{j}}{W_{W}}-a_{j W}\right| \leq \xi, \text { for all } j \\
& \sum_{j} W_{j}=1, \quad W_{j} \geq 0 \text { for all } j
\end{array}
$$

After finding the results, the consistency level of the comparisons must be achieved. The consistency ratio of BWM can be expressed by 


\begin{tabular}{l|c|c|c|c|c|c|c|c|c} 
& $\mathbf{1}$ & $\mathbf{2}$ & $\mathbf{3}$ & $\mathbf{4}$ & $\mathbf{5}$ & $\mathbf{6}$ & $\mathbf{7}$ & $\mathbf{8}$ & $\mathbf{9}$ \\
\hline Consistency index & 0.00 & 0.44 & 1.00 & 1.63 & 2.30 & 3.00 & 3.73 & 4.47 & 5.23 \\
\hline
\end{tabular}

using $\xi^{*}$ and the corresponding consistency index (Tab. 3), as follows:

$$
\text { Constistency Ratio }=\frac{\xi^{*}}{\text { Consistency index }}
$$

It can be seen that the smaller the $\xi^{*}$, the smaller the 'consistency ratio', and the more consistent the vectors are.
Experts were invited to participate in this study and evaluate factors. According to the BWM algorithm, they first must choose the best and worst factors. For this, they all agreed that $\mathrm{C}_{3}$ can be the best item and $\mathrm{C}_{8}$ is the worst attribute. Then respondents (experts) have to compare in pair the best and worst criteria to others as these two tables show. For example, $\mathrm{C}_{3}$ has 4 times more importance than $\mathrm{C}_{6}$. Then

\section{Tab. 4: Exports best, worst factor selection and pairwise comparison for BWM}

\begin{tabular}{l|c|c|c|c|c|c|c|c|c} 
Best to others & $\mathrm{C}_{1}$ & $\mathrm{C}_{2}$ & $\mathrm{C}_{3}$ & $\mathrm{C}_{4}$ & $\mathrm{C}_{5}$ & $\mathrm{C}_{6}$ & $\mathrm{C}_{7}$ & $\mathrm{C}_{8}$ & $\mathrm{C}_{9}$ \\
\hline $\mathrm{C}_{3}$ & 3 & 4 & 1 & 5 & 6 & 4 & 3 & 7 & 5 \\
\hline Others to the worst & $\mathrm{C}_{1}$ & $\mathrm{C}_{2}$ & $\mathrm{C}_{3}$ & $\mathrm{C}_{4}$ & $\mathrm{C}_{5}$ & $\mathrm{C}_{6}$ & $\mathrm{C}_{7}$ & $\mathrm{C}_{8}$ & $\mathrm{C}_{9}$ \\
\hline $\mathrm{C}_{8}$ & 3 & 4 & 5 & 6 & 5 & 3 & 5 & 1 & 4 \\
\hline
\end{tabular}

Source: own

based on the vectors of the Tab. 4, we formulate a LP model which is seen below:

\section{$\min \xi$}

s.t:

$\left|\frac{W_{3}}{W_{1}}-3\right| \leq \xi,\left|\frac{W_{3}}{W_{2}}-4\right| \leq \xi,\left|\frac{W_{3}}{W_{4}}-5\right| \leq \xi$,

$\left|\frac{W_{3}}{W_{5}}-6\right| \leq \xi,\left|\frac{W_{3}}{W_{6}}-4\right| \leq \xi,\left|\frac{W_{3}}{W_{7}}-3\right| \leq \xi$,

$\left|\frac{W_{3}}{W_{8}}-7\right| \leq \xi,\left|\frac{W_{3}}{W_{9}}-5\right| \leq \xi,\left|\frac{W_{1}}{W_{8}}-3\right| \leq \xi$,

$\left|\frac{W_{2}}{W_{8}}-4\right| \leq \xi,\left|\frac{W_{3}}{W_{8}}-5\right| \leq \xi,\left|\frac{W_{4}}{W_{8}}-6\right| \leq \xi$,

$\left|\frac{W_{5}}{W_{8}}-5\right| \leq \xi,\left|\frac{W_{7}}{W_{8}}-5\right| \leq \xi,\left|\frac{W_{9}}{W_{8}}-4\right| \leq \xi ;$

$\sum_{j=1}^{9} W_{j}=1 \quad W_{j} \geq 0$ for all $j$

The LP model is solved by LINDO or other programs and the weights are reported as seen in Tab. 3. It is seen that $\mathrm{C}_{3}$ weight is 0.28 while $\mathrm{C}_{8}$ which is the least important factor contains the importance of 0.033 .

\subsection{COmbined COmpromise SOlution (CoCoSo) Method}

CoCoSo (Yazdani et al., 2019) is a recent developed decision-making tool using an integrated form of Simple Additive Weighting (SAW) and Exponentially Weighted Product model (MEW). This method solves a decision problem using the following steps:

1 - Determining the initial decision-making matrix including criteria and alternatives as shown below:

$$
\begin{aligned}
& x_{i j}=\left[\begin{array}{ccc}
x_{11} & \cdots & x_{1 n} \\
\vdots & \ddots & \vdots \\
x_{m 1} & \cdots & x_{m n}
\end{array}\right] \\
& i=1,2, \ldots, m ; j=1,2, \ldots, n .
\end{aligned}
$$




\begin{tabular}{c|c|c|c|c|c|c|c|c|c}
\multicolumn{1}{c|}{ Weights } & $\mathbf{C}_{1}$ & $\mathbf{C}_{2}$ & $\mathbf{C}_{3}$ & $\mathbf{C}_{4}$ & $\mathbf{C}_{5}$ & $\mathbf{C}_{6}$ & $\mathbf{C}_{7}$ & $\mathbf{C}_{8}$ & $\mathbf{C}_{9}$ \\
\hline & 0.132 & 0.099 & 0.280 & 0.079 & 0.066 & 0.099 & 0.132 & 0.033 & 0.079 \\
\hline Consistency ratio & \multicolumn{10}{c}{0.117} \\
\hline
\end{tabular}

\section{Fig. 2: Computed weights of BWM}

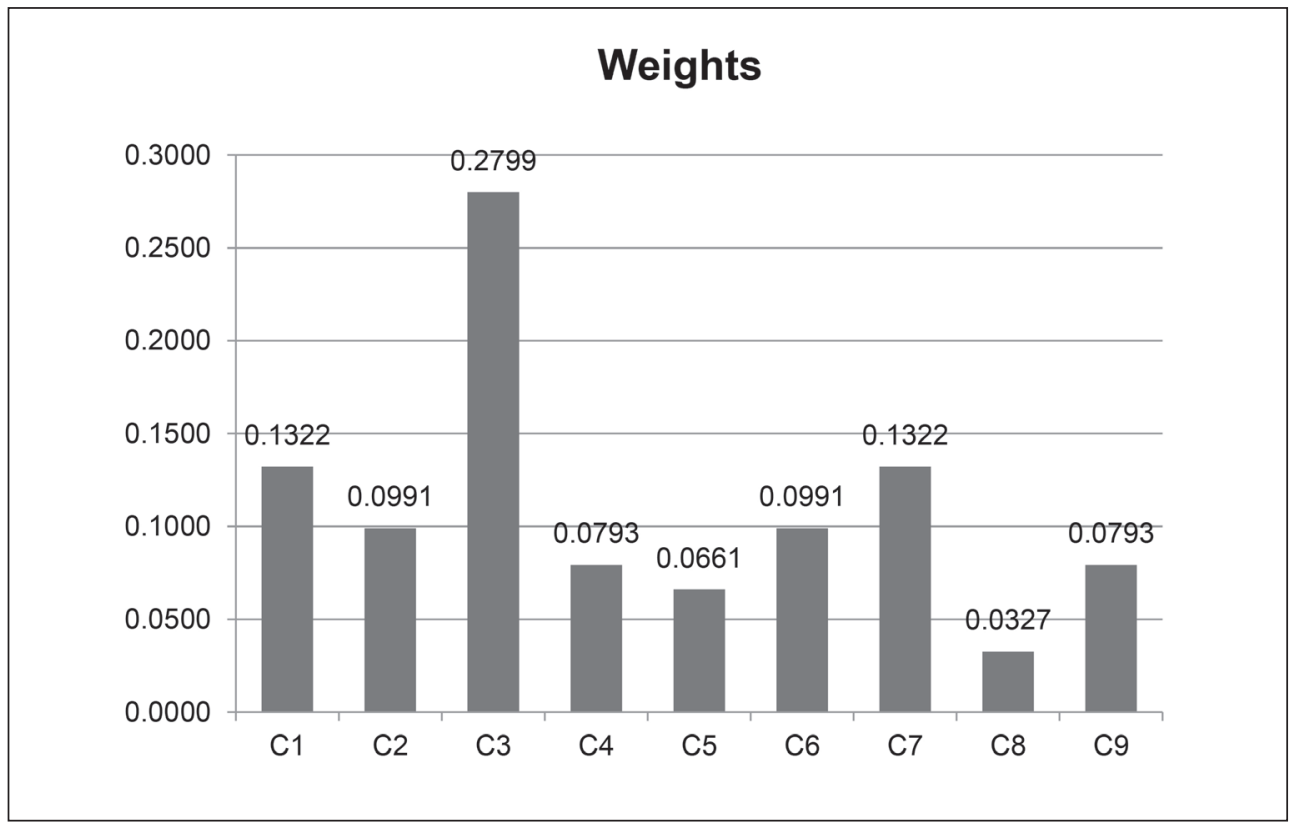

Source: own

2 - The normalisation of decision matrix is performed using:

$$
\begin{aligned}
& r_{i j}=\frac{x_{i j}-\min _{i} x_{i j}}{\max _{i} x_{i j}-\min _{i} x_{i j}} ; \text { for benefit criterion } \\
& r_{i j}=\frac{\max _{i} x_{i j}-x_{i j}}{\max _{i} x_{i j}-\min _{i} x_{i j}} ; \text { for cost criterion }
\end{aligned}
$$

3 - To catch the weighted normalized matrix for each alternative and also the power weight of comparability sequences for each alternative as $S_{i}$ and $P_{i}$, respectively:

$$
S_{i}=\sum_{j=1}^{n}\left(w_{j} r_{i j}\right)
$$

$$
P_{i}=\sum_{j=1}^{n}\left(r_{i j}\right)^{w_{j}}
$$

4 - To rate decision alternatives we have designed three formulas (6), (7), and (8), as seen here:
a) $K_{i a}=\frac{P_{i}+S_{i}}{\sum_{i=1}^{m}\left(P_{i}+S_{i}\right)}$
b) $K_{i b}=\frac{S_{i}}{\min _{i} S_{i}}+\frac{P_{i}}{\min _{i} P_{i}}$
c) $K_{i c}=\frac{\lambda\left(S_{i}\right)+(1-\lambda)\left(P_{i}\right)}{\left(\lambda \max _{i} S_{i}+(1-\lambda) \max _{i} P_{i}\right)} ; 0 \leq \lambda \leq 1$

In formula (8) $\lambda$ (usually $\lambda=0.5$ ) is chosen by decision-makers. However, the flexibility and 
stability of the proposed CoCoSo can rely on other values.

5 - The final ranking of the alternatives is determined based on $k_{i}$, values (as more significant as better):

$$
k_{i}=\left(k_{i a} k_{i b} k_{i c}\right)^{\frac{1}{3}}+\frac{1}{3}\left(k_{i a}+k_{i b}+k_{i c}\right)
$$

The process of evaluating the experts has two main sections. First, those experts who in evaluation do not have a minimum 7 in each criterion will be deleted from the final evaluation because they can be considered as a suitable expert for the study. Tab. 6 shows the first step and those experts who could not meet the main perspective of the study were highlighted in red.

The second step will be the final ranking and evaluation based on CoCoso method.
Tab. 7 indicates the required material for forming a multi criteria evaluation by CoCoSo and the BWM weights. The first step in finding best alternative in CoCoSo is to normalize the matrix, this action is performed using formulas (5) and (6). For this decision problem, all the criteria are beneficial, therefore we just need to apply formula (5). Tab. 8 draws the normalized matrix for CoCoSo. Next step is to aggregate the weights of decision factors into the decision making formulation. This task can be accomplished through the formulas (7) and (8). We obtain $S_{j}$ values which are shown in Tab. 9. The structure of CoCoSo allows us to define a Power weighted decision matrix which is shown by Tab. 10 and $P_{j}$ values are appeared in the last column. The rest of the process is to compute three aggregate functions and deliver the final priority of alternatives. We handle this

\section{Tab. 6: Evaluation matrix of the experts}

\begin{tabular}{c|c|c|c|c|c|c|c|c|c} 
& $\mathbf{C}_{1}$ & $\mathbf{C}_{2}$ & $\mathbf{C}_{3}$ & $\mathbf{C}_{4}$ & $\mathbf{C}_{5}$ & $\mathbf{C}_{6}$ & $\mathbf{C}_{7}$ & $\mathbf{C}_{8}$ & $\mathbf{C}_{9}$ \\
\hline Weights & 0.132 & 0.099 & 0.280 & 0.079 & 0.066 & 0.099 & 0.132 & 0.033 & 0.079 \\
\hline $\mathrm{A}_{1}$ & 8 & 7 & 8 & 9 & 7 & 8 & 7 & 7 & 7 \\
\hline $\mathrm{A}_{2}$ & 7 & 8 & 7 & 8 & 6 & 6 & 7 & 8 & 7 \\
\hline $\mathrm{A}_{3}$ & 6 & 5 & 7 & 6 & 5 & 6 & 5 & 6 & 7 \\
\hline $\mathrm{A}_{4}$ & 7 & 7 & 8 & 7 & 8 & 8 & 9 & 7 & 8 \\
\hline $\mathrm{A}_{5}$ & 7 & 8 & 8 & 8 & 8 & 7 & 7 & 7 & 7 \\
\hline $\mathrm{A}_{6}$ & 8 & 7 & 6 & 7 & 7 & 6 & 7 & 7 & 7 \\
\hline $\mathrm{A}_{7}$ & 7 & 8 & 8 & 7 & 8 & 9 & 8 & 8 & 7 \\
\hline $\mathrm{A}_{8}$ & 7 & 8 & 6 & 6 & 5 & 8 & 7 & 7 & 7 \\
\hline $\mathrm{A}_{9}$ & 9 & 8 & 7 & 8 & 7 & 7 & 7 & 8 & 8 \\
\hline $\mathrm{A}_{10}$ & 8 & 7 & 8 & 8 & 8 & 7 & 7 & 8 & 8 \\
\hline $\mathrm{A}_{11}$ & 5 & 6 & 5 & 6 & 7 & 6 & 7 & 4 & 5 \\
\hline $\mathrm{A}_{12}$ & 6 & 6 & 5 & 7 & 6 & 7 & 7 & 6 & 6 \\
\hline $\mathrm{A}_{13}$ & 4 & 5 & 4 & 6 & 7 & 6 & 7 & 5 & 5 \\
\hline $\mathrm{A}_{14}$ & 8 & 8 & 7 & 8 & 9 & 8 & 7 & 8 & 8 \\
\hline $\mathrm{A}_{15}$ & 5 & 6 & 7 & 7 & 6 & 7 & 8 & 5 & 6 \\
\hline $\mathrm{A}_{16}$ & 7 & 7 & 6 & 7 & 8 & 7 & 6 & 5 & 6 \\
\hline $\mathrm{A}_{17}$ & 7 & 8 & 9 & 8 & 8 & 7 & 7 & 8 & 7 \\
\hline $\mathrm{A}_{18}$ & 6 & 6 & 7 & 7 & 6 & 5 & 7 & 8 & 7 \\
\hline $\mathrm{A}_{19}$ & 8 & 7 & 8 & 7 & 8 & 9 & 8 & 8 & 7 \\
\hline $\mathrm{A}_{20}$ & 7 & 6 & 7 & 6 & 5 & 7 & 8 & 6 & 5 \\
\hline
\end{tabular}


step using formulas (9), (10), (11) and (12) and the responses are encountered in Tab. 11. CoCoSo is an effective decision tool that for this specific decision problem order the alternative ranking as:

$A_{14}>A_{7}>A_{19}>A_{10}>A 1_{7}>A_{4}>A_{9}>A_{1}>A_{5}$
Fig. 3 illustrates the preference order to decision alternatives while shows how $K$ values are close. This confirms the stability of the applied model.

\begin{tabular}{|c|c|c|c|c|c|c|c|c|c|}
\hline $\begin{array}{l}\text { Initial } \\
\text { matrix }\end{array}$ & $C_{1}$ & $\mathrm{C}_{2}$ & $\mathrm{C}_{3}$ & $\mathrm{C}_{4}$ & $\mathrm{C}_{5}$ & $\mathrm{C}_{6}$ & $C_{7}$ & $\mathrm{C}_{8}$ & $\mathrm{C}_{9}$ \\
\hline$A_{1}$ & 8 & 7 & 8 & 9 & 7 & 8 & 7 & 7 & 7 \\
\hline $\mathrm{A}_{4}$ & 7 & 7 & 8 & 7 & 8 & 8 & 9 & 7 & 8 \\
\hline $\mathrm{A}_{5}$ & 7 & 8 & 8 & 8 & 8 & 7 & 7 & 7 & 7 \\
\hline $\mathrm{A}_{7}$ & 7 & 8 & 8 & 7 & 8 & 9 & 8 & 8 & 7 \\
\hline$A_{9}$ & 9 & 8 & 7 & 8 & 7 & 7 & 7 & 8 & 8 \\
\hline$A_{10}$ & 8 & 7 & 8 & 8 & 8 & 7 & 7 & 8 & 8 \\
\hline $\mathrm{A}_{14}$ & 8 & 8 & 7 & 8 & 9 & 8 & 7 & 8 & 8 \\
\hline$A_{17}$ & 7 & 8 & 9 & 8 & 8 & 7 & 7 & 8 & 7 \\
\hline $\mathrm{A}_{19}$ & 8 & 7 & 8 & 7 & 8 & 9 & 8 & 8 & 7 \\
\hline
\end{tabular}

Source: own

\begin{tabular}{|c|c|c|c|c|c|c|c|c|c|}
\hline $\begin{array}{l}\text { Initial } \\
\text { matrix }\end{array}$ & $C_{1}$ & $\mathrm{C}_{2}$ & $\mathrm{C}_{3}$ & $\mathrm{C}_{4}$ & $\mathrm{C}_{5}$ & $\mathrm{C}_{6}$ & $C_{7}$ & $\mathrm{C}_{8}$ & $\mathrm{C}_{9}$ \\
\hline$A_{1}$ & 0.5 & 0.0 & 0.5 & 1.0 & 0.0 & 0.5 & 0.0 & 0.0 & 0.0 \\
\hline $\mathrm{A}_{4}$ & 0.0 & 0.0 & 0.5 & 0.0 & 0.5 & 0.5 & 1.0 & 0.0 & 1.0 \\
\hline $\mathrm{A}_{5}$ & 0.0 & 1.0 & 0.5 & 0.5 & 0.5 & 0.0 & 0.0 & 0.0 & 0.0 \\
\hline$A_{7}$ & 0.0 & 1.0 & 0.5 & 0.0 & 0.5 & 1.0 & 0.5 & 1.0 & 0.0 \\
\hline $\mathrm{A}_{9}$ & 1.0 & 1.0 & 0.0 & 0.5 & 0.0 & 0.0 & 0.0 & 1.0 & 1.0 \\
\hline$A_{10}$ & 0.5 & 0.0 & 0.5 & 0.5 & 0.5 & 0.0 & 0.0 & 1.0 & 1.0 \\
\hline $\mathrm{A}_{14}$ & 0.5 & 1.0 & 0.0 & 0.5 & 1.0 & 0.5 & 0.0 & 1.0 & 1.0 \\
\hline $\mathrm{A}_{17}$ & 0.0 & 1.0 & 1.0 & 0.5 & 0.5 & 0.0 & 0.0 & 1.0 & 0.0 \\
\hline $\mathrm{A}_{19}$ & 0.5 & 0.0 & 0.5 & 0.0 & 0.5 & 1.0 & 0.5 & 1.0 & 0.0 \\
\hline
\end{tabular}




\begin{tabular}{|c|c|c|c|c|c|c|c|c|c|c|}
\hline $\begin{array}{l}\text { Initial } \\
\text { matrix }\end{array}$ & $\mathrm{C}_{1}$ & $\mathrm{C}_{2}$ & $\mathrm{C}_{3}$ & $\mathrm{C}_{4}$ & $\mathrm{C}_{5}$ & $C_{6}$ & $C_{7}$ & $\mathrm{C}_{8}$ & $\mathrm{C}_{9}$ & $\mathbf{S j}$ \\
\hline$A_{1}$ & 0.066 & 0 & 0.14 & 0.079 & 0 & 0.0495 & 0 & 0 & 0 & 0.335 \\
\hline $\mathrm{A}_{4}$ & 0 & 0 & 0.14 & 0 & 0.033 & 0.0495 & 0.132 & 0 & 0.079 & 0.434 \\
\hline $\mathrm{A}_{5}$ & 0 & 0.099 & 0.14 & 0.0395 & 0.033 & 0 & 0 & 0 & 0 & 0.312 \\
\hline $\mathrm{A}_{7}$ & 0 & 0.099 & 0.14 & 0 & 0.033 & 0.099 & 0.066 & 0.033 & 0 & 0.47 \\
\hline $\mathrm{A}_{9}$ & 0.132 & 0.099 & 0 & 0.0395 & 0 & 0 & 0 & 0.033 & 0.079 & 0.383 \\
\hline$A_{10}$ & 0.066 & 0 & 0.14 & 0.0395 & 0.033 & 0 & 0 & 0.033 & 0.079 & 0.391 \\
\hline $\mathrm{A}_{14}$ & 0.066 & 0.099 & 0 & 0.0395 & 0.066 & 0.0495 & 0 & 0.033 & 0.079 & 0.432 \\
\hline$A_{17}$ & 0 & 0.099 & 0.28 & 0.0395 & 0.033 & 0 & 0 & 0.033 & 0 & 0.485 \\
\hline$A_{19}$ & 0.0660 & 0 & 0.14 & 0 & 0.033 & 0.099 & 0.066 & 0.033 & 0 & 0.437 \\
\hline
\end{tabular}

\section{Tab. 10: Power weighted matrix}

\begin{tabular}{|c|c|c|c|c|c|c|c|c|c|c|}
\hline $\begin{array}{l}\text { Initial } \\
\text { matrix }\end{array}$ & $\mathrm{C}_{1}$ & $\mathrm{C}_{2}$ & $\mathrm{C}_{3}$ & $\mathrm{C}_{4}$ & $\mathrm{C}_{5}$ & $\mathrm{C}_{6}$ & $C_{7}$ & $\mathrm{C}_{8}$ & $\mathrm{C}_{9}$ & $\mathrm{Pj}$ \\
\hline$A_{1}$ & 0.9126 & 0 & 0.8236 & 1 & 0 & 0.9337 & 0 & 0 & 0 & 3.67 \\
\hline $\mathrm{A}_{4}$ & 0 & 0 & 0.8236 & 0 & 0.9553 & 0.9337 & 1 & 0 & 1 & 4.71 \\
\hline$A_{5}$ & 0 & 1 & 0.8236 & 0.9467 & 0.9553 & 0 & 0 & 0 & 0 & 3.73 \\
\hline$A_{7}$ & 0 & 1 & 0.8236 & 0 & 0.9553 & 1 & 0.9126 & 1 & 0 & 5.69 \\
\hline $\mathrm{A}_{9}$ & 1 & 1 & 0 & 0.9467 & 0 & 0 & 0 & 1 & 1 & 4.95 \\
\hline$A_{10}$ & 0.9126 & 0 & 0.8236 & 0.9467 & 0.9553 & 0 & 0 & 1 & 1 & 5.64 \\
\hline $\mathrm{A}_{14}$ & 0.9126 & 1 & 0 & 0.9467 & 1 & 0.9337 & 0 & 1 & 1 & 6.79 \\
\hline$A_{17}$ & 0 & 1 & 1 & 0.9467 & 0.9553 & 0 & 0 & 1 & 0 & 4.90 \\
\hline $\mathrm{A}_{19}$ & 0.9126 & 0 & 0.8236 & 0 & 0.9553 & 1 & 0.9126 & 1 & 0 & 5.60 \\
\hline
\end{tabular}

\section{Tab. 11: Alternative score computation and aggregate ranking of CoCoSo}

\begin{tabular}{c|c|c|c|c|c|c|c|c} 
Alternatives & $\mathbf{K a}$ & $\begin{array}{c}\text { rank } \\
\text { (a) }\end{array}$ & $\mathbf{K b}$ & $\begin{array}{c}\text { rank } \\
\text { (b) }\end{array}$ & $\mathbf{K c}$ & $\begin{array}{c}\text { rank } \\
\text { (c) }\end{array}$ & $\mathbf{K}$ & $\begin{array}{c}\text { Aggregated } \\
\text { ranking }\end{array}$ \\
\hline $\mathrm{A}_{1}$ & 0.0811 & 9 & 2.0738 & 8 & 0.5502 & 9 & 1.3541 & 8 \\
\hline $\mathrm{A}_{4}$ & 0.1043 & 7 & 2.6758 & 6 & 0.7071 & 7 & 1.7445 & 6 \\
\hline $\mathrm{A}_{5}$ & 0.0818 & 8 & 2.0152 & 9 & 0.5547 & 8 & 1.3344 & 9 \\
\hline $\mathrm{A}_{7}$ & 0.1248 & $\mathbf{2}$ & 3.0597 & $\mathbf{2}$ & 0.8466 & $\mathbf{2}$ & 2.0301 & $\mathbf{2}$ \\
\hline $\mathrm{A}_{9}$ & 0.1080 & 6 & 2.5759 & 7 & 0.7323 & 6 & 1.7271 & 7 \\
\hline $\mathrm{A}_{10}$ & 0.1221 & 4 & 2.7900 & 5 & 0.8284 & 4 & 1.9028 & 4 \\
\hline $\mathrm{A}_{14}$ & 0.1464 & $\mathbf{1}$ & 3.2379 & $\mathbf{1}$ & 0.9928 & $\mathbf{1}$ & 2.2368 & $\mathbf{1}$ \\
\hline $\mathrm{A}_{17}$ & 0.1091 & 5 & 2.8911 & 4 & 0.7402 & 5 & 1.8626 & 5 \\
\hline $\mathrm{A}_{19}$ & 0.1224 & 3 & 2.9299 & 3 & 0.8301 & 3 & 1.9618 & 3 \\
\hline
\end{tabular}




\section{Fig. 3: Comparison of different rank strategy by CoCoSo}

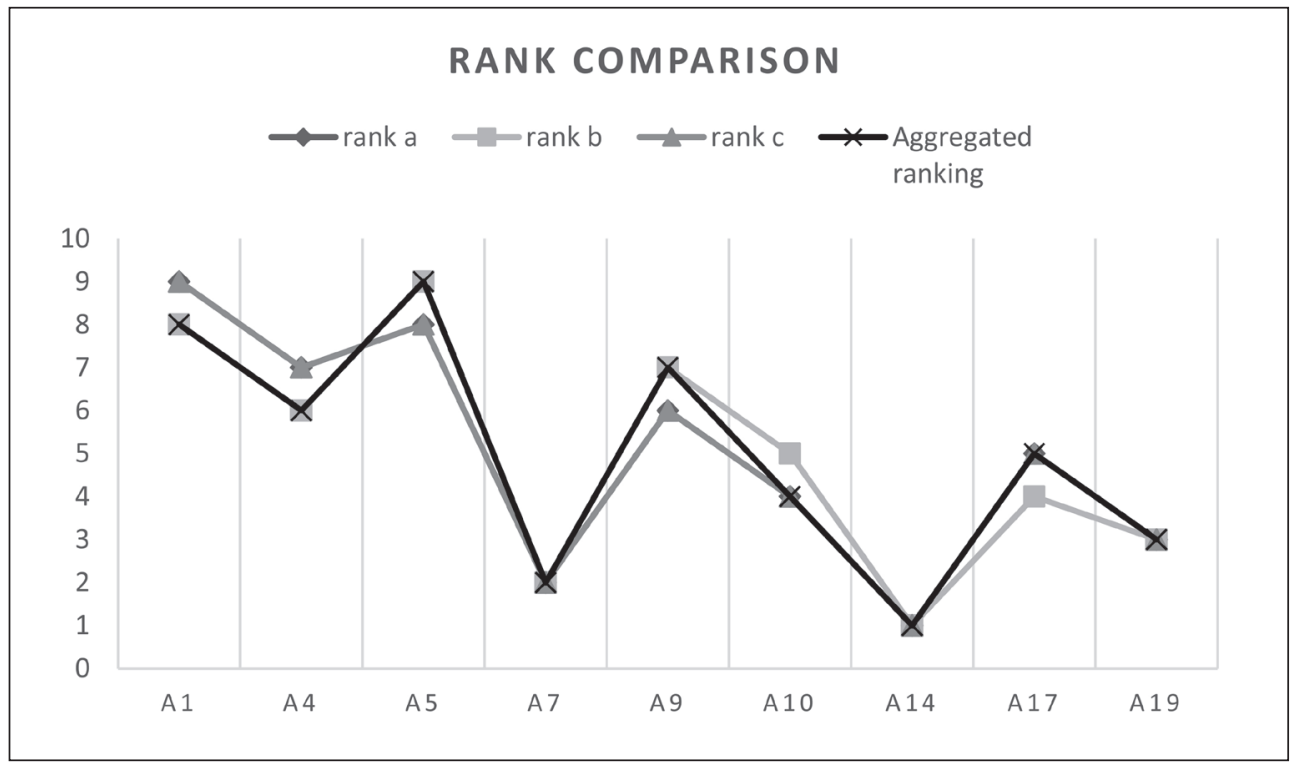

Source: own

\section{Conclusion}

The field of MADM has been fast growing field in the new century in the outline of decision making. The rate of introducing new methods has increased and more additive complicated mathematical models such as fuzzy and grey numbers added to the field but it feels still there are some deficiencies in the concept. PMADM has introduced to add a platform to the classic structure of MADM to compensate the deficiencies of classic MADM as much it can.

In this study discussed about how a qualitative method, CLA, which used to apply in classic "Futures Studies" investigates can lead a mathematical field which definitely needs qualitative data as well. As it was mentioned, usually CLA has been applying as a support system for studies about the future and the main idea came from this characteristic of CLA which can tie with other methods, approaches and structures really well.

There are not so many studies about evaluating experts who are cooperating in a Multi-Attribute solving method. Usually it is up to the investigators and researchers to select the best qualified experts in the field of study which can be multi-disciplinary as well without any limitation. Also as it investigated above about a published research based on CLA method, experts should believe in those positive changes which researchers are really trying to design and plan. So, here the role of CLA can be seen which it shows how those four deep levels can prove us are researchers of a study going to select an appropriate person for their studies or no.

In so many common decision making problems, real data can make the role of experts lighter but it should not be forget data future and all studies about that need more qualitative data which mean experts probably will have more role in that and our probable future is creating with their minds. Eventually, this study can be a help for the all researchers to select better experts regarding to their studies which are not probably short-term and unrelated to the society. 


\section{References}

Arms, H., Wiecher, M., \& Kleiderman, V. (2012). Dynamic models for managing big decisions. Strategy \& Leadership, 40(5), 39-46. https://doi.org/10.1108/10878571211257177

Baradaran Ghahfarokhi, M., Mohaghar, A., \& Saghafi, F. (2018). The futures of the University of Tehran using causal layered analysis. Foresight, 20(4), 393-415. https://doi. org/10.1108/FS-01-2018-0001

Durbach, I. N., \& Stewart, T. J. (2012). Modeling uncertainty in multi-criteria decision analysis. European Journal of Operational Research, 223(1), 1-14. https://doi. org/10.1016/j.ejor.2012.04.038

Ginevičius, R. (2011). A New Determining Method for the Criteria Weights in MultiCriteria Evaluation. International Journal of Information Technology \& Decision Making, 10(6), 1067-1095. https://doi.org/10.1142/ S0219622011004713

González-Prida, V., Viveros, P., Barberá, L., \& Crespo Márquez, A. (2014). Dynamic analytic hierarchy process: AHP method adapted to a changing environment. Journal of Manufacturing Technology Management, 25(4), 457-475. https://doi.org/10.1108/JMTM03-2013-0030

Hashemkhani Zolfani, S. (2018). Futures Studies Based on Decision Making Methods (Doctoral dissertation - in Persian). Tehran: Amirkabir University of Technology.

Hashemkhani Zolfani, S., Aghdaie, M. H., Derakhti, A., Zavadskas, E. K., \& Morshed Varzandeh, M. H. (2013). Decision making on business issues with foresight perspective; an application of new hybrid MCDM model in shopping mall locating. Expert Systems with Applications, 40(17), 7111-7121. https://doi. org/10.1016/j.eswa.2013.06.040

Hashemkhani Zolfani, S., Maknoon, R., \& Zavadskas, E. K. (2016a). Multiple attribute decision making (MADM) based scenarios. International Journal of Strategic Property Management, 20(1), 101-111. https://doi.org/1 $0.3846 / 1648715 X .2015 .1132487$

Hashemkhani Zolfani, S., Maknoon, R., \& Zavadskas, E. K. (2016b). An introduction to Prospective Multiple Attribute Decision Making (PMADM). Technological and Economic Development of Economy, 22(2), 309-326. https://doi.org/10.3846/20294913.2016.1150363

Hashemkhani Zolfani, S., Maknoon, R., \& Zavadskas, E. K. (2016c). MADM and Futures
Studies; A necessity. In Proceedings of the 9th International Scientific Conference "Business and Management 2016" (pp. 1-7). http://dx.doi. org/10.3846/bm.2016.62

Hashemkhani Zolfani, S., \& Masaeli, R. (2019). From Past to Present and into the Sustainable Future: PMADM Approach in Shaping Regulatory Policies of Medical Device Industry in the New Sanction Period. In P. Chatterjee, M. Yazdani, \& S. Chakraborty (Eds.), Sustainability Modeling in Engineering; A multi-Criteria Perspective (pp. 73-95). Singapore: Word Scientific. https://doi. org/10.1142/9789813276338_0003

Hashemkhani Zolfani, S., Yazdani, M., \& Zavadskas, E. K. (2018a). An extended stepwise weight assessment ratio analysis (SWARA) method for improving criteria prioritization process. Soft Computing, 22(22), 7399-7405. https://doi.org/10.1007/s00500018-3092-2

Hashemkhani Zolfani, S., Zavadskas, E. K., Khazaelpour, P., \& Cavallaro, F. (2018b). The Multi-Aspect Criterion in the PMADM Outline and Its Possible Application to Sustainability Assessment. Sustainability, 10(12), 4451. https://doi.org/10.3390/su10124451

Heinonen, S., Minkkinen, M., Karjalainen, J., \& Inayatullah, S. (2017). Testing transformative energy scenarios through causal layered analysis gaming. Technological Forecasting \& Social Change, 124, 101-113. https://doi. org/10.1016/j.techfore.2016.10.011

Inayatullah, S. (1998). Causal Layered Analysis. Futures, 30(8), 815-829. https://doi. org/10.1016/S0016-3287(98)00086-X

Jassbi, J. J., Ribeiro, R. A., \& Varela, L. R. (2014). Dynamic MCDM with future knowledge for supplier selection. Journal of Decision Systems, 23(3), 232-248. https://doi.org/10.10 80/12460125.2014.886850

Ketonen-Oksi, S. (2018). Creating a shared narrative: the use of causal layered analysis to explore value co-creation in a novel service ecosystem. European Journal of Futures Research, 6, 5, https://doi.org/10.1186/s40309018-0135-y

Milojević, I. (2015). Conclusion. In S. Inayatullah \& I. Milojević (Eds.), CLA 2.0 transformative research in theory and practice (pp. 535-557). New Taipei City: Tamkang University.

Milojević, I. \& Inayatullah, S. (2015). Narrative foresight. Futures, 73, 151-162. https://doi.org/10.1016/j.futures.2015.08.007 
Mukhametzyanov, I., \& Pamučar, D. (2018). A sensitivity analysis in MCDM problems: Astatistical Approach. Decision Making: Applications in Management and Engineering, 1(2), 51-80. https://doi.org/10.31181/dmame1802050m

Ondrus, J., Bui, T., \& Pigneur, Y. (2015). A foresight support system using MCDM methods. Group Decision and Negotiation, 24(2), 333-358. https://doi.org/10.1007/ s10726-014-9392-8

Pamučar, D., Stević, Z., \& Sremac, S. (2018). A New Model for Determining Weight Coefficients of Criteria in MCDM Models: Full Consistency Method (FUCOM). Symmetry, 10(9), 393. https://doi.org/10.3390/ sym 10090393

Pamučar, D., Božanić, D., \& Ranđelović, A. (2017). Multi-Criteria Decision Making: An example of sensitivity analysis. Serbian Journal of Management, 12(1), 1-27. https://doi. org/10.5937/sjm12-9464

Ramos, J. M. (2003). From critique to cultural recovery: critical futures studies and causal layered analysis. (Monograph Series 2003 No. 2). Melbourne: Australian Foresight Institute Swinbourne University.

Rezaei, J. (2015). Best-worst multi-criteria decision-making method. Omega, 53, 49-57. https://doi.org/10.1016/j.omega.2014.11.009

Saaty, T. L. (1980). The Analytical Hierarchy Process. New York, NY: McGraw-Hill.

Saaty, T. L. (1996). Decision Making in Complex Environments, The Analytical Hierarchy Process for Decision Making with Dependence and Dependence and Feedback. Pittsburgh, PA: RWS Publications.

Saaty, T. L. (1999). Fundamentals of analytic network process. In Proceedings of the International Symposium on the Analytic Hierarchy Process, 12-14 August 1999 (pp. 348-379). Kobe, Japan.

Siddiqi, A., Ereiqat, F., \& Anadon, L. D. (2016). Formulating Expectations for Future Water Availability through Infrastructure Development Decisions in Arid Regions. Systems Engineering, 19(2), 101-110. https://doi.org/10.1002/sys.21337

Tadić, S. R., Zečević, S. M., \& Krstić, M. D. (2014). Ranking of logistics system scenarios for central business district. Promet - Traffic \& Transportation, 26(2), 159-167. https://doi. org/10.7307/ptt.v26i2.1349

Toloie Eshlaghy, A., Rastkhiz Paydar, N., Joda, K., \& Rastkhiz Paydar, N. (2009). Sensitivity analysis for criteria values in decision making matrix of SAW method. International Journal of Industrial Mathematics, 1(1), 69-75.

Triantaphyllou, E., \& Sánchez, A. (1997). A Sensitivity Analysis Approach for Some Deterministic Multi-Criteria Decision-Making Methods. Decision Sciences, 28(1), 151-194. https://doi.org/10.1111/j.1540-5915.1997.tb01306.x

Trutnevyte, E., Stauffacher, M., \& Scholz, R. W. (2012). Linking stakeholder visions with resource allocation scenarios and multi-criteria assessment. European Journal of Operational Research, 219(3), 762-772. https://doi. org/10.1016/j.ejor.2012.01.009

Wang, Y., Shi, X., Sun, J., \& Qian, W. (2014). A grey interval relational degree-based dynamic multi-attribute decision making method and its application in investment decision making. Mathematical Problems in Engineering, 1, 1-6. http://dx.doi.org/10.1155/2014/607016

Yazdani, M., Zavadskas, E. K., Ignatius, J., \& Doval Abad, M. (2016). Sensitivity Analysis in MADM Methods: Application of Material Selection. Inzinerine Ekonomika-Engineering Economics, 27(4), 382-391. https://doi. org/10.5755/j01.ee.27.4.14005

Yazdani, M., Zarate, P., Zavadskas, E. K., \& Turskis, Z. (2019). A Combined Compromise Solution (CoCoSo) method for multi-criteria decision-making problems. Management Decision, 57(9), 2501-2519. https://doi. org/10.1108/MD-05-2017-0458

Zavadskas, E. K., Turskis, Z., Dejus, T., \& Viteikienè, M. (2007). Sensitivity analysis of a simple additive weight method, International Journal of Management and Decision Making, 8(5/6), 555-574. https://doi.org/10.1504/ IJMDM.2007.013418

Zhang, Z. (2012). An approach to dynamic multi-attribute decision making for choosing green supplier. Journal of Convergence Information Technology, 7(21), 261-269. https://doi.org/10.4156/jcit.vol7.issue21.33 